\title{
Condicionantes Macroeconômicos e Regulatórios da Determinação da Capacidade Produtiva: Estudo de Caso do Setor Aéreo
}

\author{
- Humberto Filipe de ANdrade Januário BettinI* \\ - Alessandro Vinícius Marques de Oliveira **
}

\begin{abstract}
RESUMO
Este trabalho objetiva identificar fatores macroeconômicos, regulatórios e concorrenciais que afetam a decisão de empresas quanto ao dimensionamento de sua capacidade produtiva. Foi desenvolvido um estudo de caso do transporte aéreo - aproveitando de uma especificidade do setor - que requer a tomada de decisão quanto à capacidade em cada submercado (par de aeroportos) operado. Buscou-se identificar o processo decisório das firmas utilizando-se um painel de dados tridimensional desagregado ao nível da empresa-mercado-tempo. Resultados finais mostraram que: I. agregados macroeconômicos, como o PIB e a taxa de câmbio, têm impacto estatisticamente significante na formação da capacidade; 2 . as medidas advindas do período da quase-desregulamentação do setor, a partir de $200 \mathrm{I}$, tiveram pouco impacto sobre a capacidade, medida pela oferta de assentos; e, por fim, 3. a associação estabelecida entre as duas maiores empresas do setor, em 2003, teve impactos relevantes, ilustrando o fato de que maior dominância afeta a tomada de decisão quanto à oferta, e requer, assim, maior acompanhamento antitruste.
\end{abstract}

\section{Palavras-Chave}

Transporte aéreo, dimensionamento da capacidade, regulação econômica

\section{ABSTRACT}

This article aims at identifying elements that affect the decision firms make in what concerns productive capacity setting in markets. Among these elements, macroeconomic, regulatory and competition factors are highlighted. In this paper, a case study for the domestic scheduled airline industry is developed, taking advantage of the particularity of this sector, in which an airline ought to decide capacities in each sub-market (pair of airports) where it is present. By using a three-dimensional panel of data (airline-market-time), we propose an identification of this decision-making process. Among the final results, it can be highlighted that: I. macroeconomic aggregates such as GDP and exchange rate have significant impact over the decision process of capacity setting; 2. liberalizing measures adopted in $200 \mathrm{I}$ and lasting for the two following years had little impact over seat supply; 3. the commercial agreement the two biggest Brazilian airlines signed in 2003 did impact the market capacity, what shows that stronger market dominance influences the decision airlines make in what concerns their supply, a result justifying an increased surveillance to be undertaken by antitrust authorities.

KEYWORDS

Air transportation, capacity setting, economic regulation

\section{JEL CLASSIFICATION}

$L 13, L 50, L 93$

\footnotetext{
* Pesquisador do Núcleo de Economia dos Transportes, Antitruste e Regulação (NECTAR) do Instituto Tecnológico de Aeronáutica (ITA) e Doutorando em Teoria Econômica pelo Instituto de Economia da Unicamp. Endereço para contato: Instituto de Economia, Universidade Estadual de Campinas. Caixa Postal: 6 I 35 - CEP I 3083-857 - Campinas - SP - Brasil. E-mail: humberto.bettini@gmail.com.

** Diretor-Executivo do Núcleo de Economia dos Transportes, Antitruste e Regulação (NECTAR) do Instituto Tecnológico de Aeronáutica (ITA). Endereço para contato: Instituto Tecnológico de Aeronáutica, Engenharia de Infraestrutura Aeronáutica. Praça Marechal Eduardo Gomes, 50 - Centro Técnico Aeroespacial - Vila das Acácias - CEP 12228-900 - São José dos Campos - SP - Brasil. E-mail: a.v.m.oliveira@gmail.com

(Recebido em agosto de 2007. Aceito para publicação em janeiro de 2008).
} 


\section{INTRODUÇÃO}

A decisão quanto à capacidade produtiva que uma empresa instala para atender à demanda de mercado é um aspecto mandatório da estratégia empresarial e não está isenta da incerteza que permeia o mundo dos negócios: fluxo de receitas futuras, padrões de reação da concorrência, custos irrecuperáveis, dentre outros aspectos de difícil avaliação ex-ante fazem-se presentes. No entanto, investigações empíricas pormenorizadas podem identificar regularidades neste aspecto decisório. Neste âmbito de investigar a forma como a oferta é dimensionada, este artigo busca apresentar evidências quanto ao impacto que políticas públicas - nomeadamente a política econômica e as questóes regulatórias - geram sobre a oferta das empresas, sem, no entanto, desconsiderar aspectos concorrenciais que também contribuem para esta tomada de decisão. Com este intuito, foi realizado um estudo de caso utilizando-se dados de oferta de empresas aéreas regulares de transporte de passageiros em suas operações domésticas no período compreendido entre o segundo semestre de 1998 e o final de 2004.

A escolha do transporte aéreo como tema de estudo deve-se à importância econômica que esta atividade apresenta. Dentre as razões que justificam o estudo econômico da aviação comercial, deve-se notar sua contribuição para a inserção internacional do País em fluxos comerciais, culturais e turísticos, bem como os impactos que engendra sobre as contas externas, por meio de receitas auferidas e de despesas realizadas em moeda internacional. Atendo-se unicamente ao cenário nacional, a aviação regular provê um pilar fundamental para a integração nacional - ao respaldar os processos de crescimento econômico e de desenvolvimento do País - e exerce impactos diretos no crescimento econômico; por ser uma atividade reconhecidamente elástica à renda, em períodos de crescimento econômico, a demanda por tráfego aéreo cresce em proporção superior à atividade econômica e acaba por reforçar o próprio crescimento, em um movimento semelhante a um efeito multiplicador, com encadeamentos à jusante e à montante. Exemplos disso são os impactos do transporte aéreo sobre o turismo, a qualificação de mão-de-obra e a geração de investimentos em infraestrutura de transportes.

Na decorrência destes aspectos, observa-se que, desde o início da aviação comercial, este setor foi submetido a políticas públicas e à regulação econômica. No entanto, as diretrizes na base desta atuação pública não permaneceram inalteradas ao longo das últimas décadas. Lovadine e Oliveira (2005) destacam os seis distintos períodos regulatórios que estiveram em vigor no Brasil nas últimas três décadas ${ }^{1}$ e evidenciam de que forma os termos aplicados às tarifas praticadas, à entrada de novos

1 Regulação com Política Industrial (1973-1986), Regulação com Política de Estabilização Ativa (19861992), Liberalização com Política de Estabilização Inativa (1992-1997), Liberalização com Restrição 
concorrentes, à competição efetiva entre as empresas incumbentes e à utilização da infraestrutura aeronáutica evoluíram ao longo destes anos.

Naturalmente, não há razões para supor que o arcabouço presente seja definitivo, uma vez que a regulação econômica da aviação comercial permanece um tema controverso, tanto no debate acadêmico quanto na condução da política econômica. Dentre outros exemplos possíveis, o limite de 20\% na propriedade estrangeira de empresas aéreas brasileiras, os critérios para a concessão de linhas aéreas e as regras para a concessão de slots em aeroportos congestionados passam por um questionamento contínuo. Por não ser um tema estritamente brasileiro, a discussão acerca de tópicos desta mesma natureza também tem lugar no exterior e nas relações entre as nações; a título de ilustração, citam-se a polêmica ao redor do Wright Amendment ${ }^{2}$, nos EUA, e as regras de reciprocidade para tráfego aéreo internacional, bem como os termos de acordos de céus abertos entre nações soberanas, fatores que conduzem a uma quebra potencial generalizada de reservas de mercado nacional.

Atendo-se ao Brasil, o momento atual é bastante propício à discussão sobre questões regulatórias aplicadas à aviação comercial. Muito recentemente (em março de 2006), pondo fim a alguns anos de debate em esferas legislativas nacionais, ocorreu uma alteração institucional significativa no setor, marcada pelo encerramento do Departamento de Aviação Civil (DAC), órgão com atribuições fundamentalmente técnicas, o qual cedeu lugar para a Agência Nacional de Aviação Civil (ANAC). Esta transição - assim como o processo prévio de debates - deu um ímpeto renovado para a discussão a respeito do estado atual dos marcos regulatórios brasileiros. Outro fato recente que estimula o estudo da matéria regulatória refere-se à forma como rotas e o acesso a aeroportos hoje concedidos à VARIG seriam alocados a outras empresas aéreas no caso de a empresa gaúcha encerrar definitivamente as suas atividades. A importância desta questão é realçada devido ao fato de o acesso ao aeroporto ser reconhecido como um dos fatores que conferem poder de mercado a uma empresa aérea, fato estilizado ilustrado por Evans e Kessides (1993) e por Borenstein (1989).

Inserindo-se nesta discussão a respeito da eficácia das políticas regulatórias, este artigo dedicará sua análise à compreensão dos fatores que condicionam a decisão quanto ao dimensionamento da capacidade das empresas aéreas nacionais de trans-

de Política de Estabilização (1998-2001), Quase-Desregulamentação (2001-2002) e Re-regulação (a partir de 2003), respectivamente.

2 A definição de empresa aérea de grande porte originalmente designa as empresas aéreas que, durante o período de regulação com política industrial (1973-1986 - ver nota 1), foram incumbidas de voar linhas aéreas nacionais-tronco e voos internacionais: Cruzeiro do Sul, TransBrasil, VARIG e VASP integravam esta lista. Embora a nomenclatura tenha perdido parcela de seu poder classificatório, inclusive por conta de alterações regulatórias relevantes ao longo das últimas décadas, o termo "empresas aéreas de grande porte" geralmente contrapóe-se às empresas aéreas de pequeno porte, comumente chamadas de "empresas aéreas regionais". No caso do período que analisamos, consideramos GOL, TAM, TransBrasil, VARIG e VASP como empresas aéreas de grande porte. 
porte regular de passageiros, por meio da utilização de técnicas econométricas. Deve-se ressaltar que o conhecimento acerca destes fatores condicionantes possui importância para os diversos agentes envolvidos com a indústria do transporte aéreo: primeiramente, empresas aéreas têm necessidade de conhecer os determinantes da capacidade ofertada por suas concorrentes; à sociedade, entidade beneficiada pela oferta de assentos disponíveis nos mercados, é facultado o direito de conhecer de que forma a oferta de assentos se comporta diante de variações de circunstâncias regulatórias e concorrenciais.

Em segundo lugar, em seu papel de regulação, órgãos de acompanhamento econômico e de defesa da concorrência devem estar munidos de estudos que thes permitam saber identificar os determinantes da alocação de oferta, assim como avaliar os impactos advindos de suas normas aplicadas ao setor. Isto porque tanto a competição predatória quanto o exercício de poder de mercado são situações que, embora polares, guardam relação com a capacidade instalada existente e a concentração dos mercados; autoridades aeroportuárias e aeronáuticas utilizam informações acerca das ofertas planejada e efetuada pelas empresas aéreas em seus processos de dimensionamento da capacidade que aeroportos e o espaço aéreo devem possuir para comportar, com níveis aceitáveis de segurança e de conforto, a operação das empresas aéreas.

Por fim, também os fabricantes e as empresas de aluguel (leasing) de aeronaves necessitam saber qual é a sensibilidade que o nível de atividade das operadoras de aeronaves comerciais possui em relação a diversos aspectos de natureza econômica para que suas ações comerciais e produtivas possam ser planejadas.

Na sequência desta introdução ao tema e da apresentação das justificativas que o suportam em sua ênfase quanto a aspectos regulatórios, o artigo será organizado da seguinte maneira: a seção 1 apresentará uma visão geral acerca de fatores que condicionam o processo decisório de uma empresa aérea no que se refere ao dimensionamento da capacidade produtiva instalada e da quantidade de assentos que ela disponibiliza nos mercados em que opera. A seção 2 apresentará o modelo empírico proposto e estimado, a base de dados, a metodologia empregada para a análise e uma discussão a respeito dos resultados obtidos. A terceira e última seção trará notas conclusivas e algumas reflexões quanto a aperfeiçoamentos que poderiam dar sequência a esta pesquisa. 


\section{A DETERMINAÇÃO DA CAPACIDADE PRODUTIVA PELAS EMPRESAS AÉREAS}

A literatura dedicada ao estudo da oferta no transporte aéreo regular de passageiros identifica diferentes níveis em que uma empresa aérea decide a magnitude de sua capacidade produtiva. Sumariamente, dentre os inúmeros níveis possíveis, podem-se destacar algumas etapas:

a. a escolha quanto ao número e ao tamanho dos avióes que comporão a frota de uma empresa aérea;

b. a configuração interna destas aeronaves;

c. a forma e a abrangência da rede de voos;

d. o número de voos operados por ligação e a alocação das aeronaves para cumprirem uma determinada programação de voos;

e. acordos operacionais com outras empresas aéreas para o compartilhamento de assentos;

f. a adoção de práticas de controle de estoque de assentos.

Todas estas etapas representam circunstâncias em que ocorrem decisões a respeito do nível de capacidade produtiva de uma empresa aérea, compreendida enquanto oferta de assentos-quilômetros. A ordem em que estas esferas de decisão estão expostas acima não necessariamente implica um ordenamento segundo sua importância para a lucratividade ou a perenidade da empresa aérea. A ordem de enumeração apenas reflete, de forma geral, graus crescentes de reversibilidade das ações. O que importa ressaltar é que nenhuma destas etapas é indiferente na geração de impactos sobre receitas potenciais e custos para a empresa aérea. Assim, todas estas questões são passíveis de serem inseridas no problema de maximização de lucros da empresa aérea.

Discorrendo sumariamente a respeito de algumas das etapas acima enumeradas, podem-se evidenciar os impactos que estas decisões exercem sobre receitas e custos para uma empresa aérea. No que se refere à etapa de composição de frota, Röller e Sickles (1997) propuseram um modelo de competição de empresas aéreas duopolistas em dois estágios e, aplicando-o à indústria do transporte aéreo na Europa para as décadas de 1970 e 1980, encontram evidências de que o dimensionamento da frota traz impactos posteriores no comportamento competitivo das empresas, ou seja, na maneira como os preços são formados e, por conseguinte, na forma como se adquire e exerce poder de mercado. Ou seja, obtiveram evidências de que a composição da frota possui uma contrapartida estratégica para a empresa aérea, ao determinar 
a inserção competitiva desse tipo de empresa e o poder de mercado que a mesma poderá usufruir.

No que concerne à etapa de decisão sobre a forma e a abrangência da rede de voos, seus impactos sobre a lucratividade da empresa aérea são tais que este tema foi tópico de estudo em inúmeros trabalhos, especialmente de origem norte-americana, por conta da mudança marcante ocorrida na forma das redes das empresas aéreas daquele país, na sequência do processo de desregulamentação, ocorrido ao final da década de 1970. Segundo verificaram Borenstein (1989), Evans e Kessides (1993) e Oum, Zhang e Zhang (1995), dentre outros, assistiu-se a uma progressiva transição de redes lineares - nas quais predominam pares de aeroportos servidos diretamente, sem a presença de escalas intermediárias ou de conexões em aeroportos de captação e redistribuição de passageiros (bubs) - para redes na forma hub \& spoke, ou seja, com a predominância de voos que se originam de uma porção diminuta de aeroportos centrais.

Os efeitos econômicos desta transição ao consumidor não tardaram a ser percebidos e pesquisados. Conforme os autores acima citados, percebeu-se que a existência de hubs conferia poder de mercado à empresa aérea que o dominasse. Dentre as razões para este maior poder de mercado, Evans e Kessides (1993) apontaram para a propriedade de recursos aeroportuários, cujo investimento é caro e cuja disponibilidade é escassa, tais como portões de embarque e, em algumas ocasiões, a totalidade de terminais de passageiros. Borenstein (1989) apontou para a existência de propriedade sobre slots de operações, a reputação de abrangência de rede adquirida, a existência de programas de passageiros frequentes e até mesmo as relações existentes com canais locais de venda de passagens (agentes de viagens locais).

Outro fator adicional para explicar o poder de mercado que pode ser exercido em ligações pertencentes a uma rede com a presença de hub é a redução no schedule delay que se impõe aos passageiros potenciais ou efetivos. Este conceito, muito recorrente em análise de transportes, refere-se à incompatibilidade iminente entre a grade de horários de partidas e chegadas de uma empresa aérea e as necessidades do passageiro individual. Conforme a valoração que o passageiro dá a seu tempo, esta incompatibilidade pode gerar uma escolha por uma empresa aérea rival, por uma rota alternativa, por um outro meio de transporte ou até mesmo por não realizar a viagem e retirar-se deste mercado. Uma rede em formato de hub \& spoke, porém, contribui para o adensamento das ligações, uma vez que cada voo atende não somente ao tráfego local, mas também à parcela de passageiros que está em trânsito de ou para o aeroporto hub. Nestas condições, um fato geralmente observado é o aumento da frequência de partidas, o que contribui para reduzir - ou mesmo eliminar - o schedule delay imposto aos passageiros das ligações. 
Similarmente ao que ocorre com a decisão quanto à composição de frotas, a decisão quanto à forma de organizar a rede de uma empresa aérea é permeada por considerações estratégicas. A este respeito, Oum, Zhang e Zhang (1995) formularam um modelo hipotético e verificaram que, sob poucas hipóteses simplificadoras a respeito da estrutura de custos das empresas aéreas, a decisão de formar uma estrutura de rede no formato hub és spoke é uma estratégia dominante, ou seja, uma empresa aérea possuiria sempre, sob as condições apontadas em seu modelo, incentivo para organizar sua rede segundo o formato de hub es spoke para obter vantagens de custo e de poder de mercado sobre as empresas concorrentes e até mesmo ser capaz de barrar a eventual entrada de novas empresas aéreas nos mercados atendidos.

Quanto às demais etapas de decisão em capacidade, empresas aéreas podem dispor de liberdade para estabelecer acordos comerciais com outras empresas aéreas, seja em regime de sobreposição (quando as empresas que entram em acordo já exploravam os mercados anteriormente, porém de maneira individual), seja de complementação de rotas, podendo haver, em ambos os casos, coordenação de horários e compartilhamento de assentos. Estes acordos permitem que a capacidade de cada empresa participante seja alterada, pois pode incluir uma permissão para que uma empresa aérea venda assentos em voos operados pela empresa parceira, o que gera disponibilização dupla dos assentos cobertos pelos termos do acordo e, consequentemente, alteração real na capacidade de cada empresa envolvida. No entanto, a variação na capacidade pode ocorrer também devido a medidas de racionalização da oferta, ou seja, por meio da supressão de frequências antes operadas por uma ou por todas as empresas aéreas participantes de um acordo de compartilhamento de assentos.

No Brasil, houve recentemente um amplo acordo operacional de code-share entre empresas aéreas regulares nacionais entre o segundo trimestre de 2003 e o segundo trimestre de 2005, envolvendo TAM e VARIG. O impacto deste acordo na oferta de serviço de transporte aéreo no mercado doméstico mostrou-se inequívoco: a suspensão conjunta e simultânea de voos rentáveis serviu de subsídio para que a Secretaria de Acompanhamento Econômico do Ministério da Fazenda (SEAE/MF) identificasse indícios de conduta de cartel e realizasse estudos que culminaram em pareceres e em um julgamento para o caso (SEAE/MF 2004), o qual resolveu pela reversão do acordo entre as empresas envolvidas.

Finalmente, hoje em dia é comum que as empresas aéreas pratiquem discriminação de preços com o suporte de ferramentas de gerenciamento de receitas (yield management). A existência desta rotina no processo de vendas das empresas aéreas significa que, mesmo havendo a previsão da ocorrência da frequência e estando um determinado equipamento designado para cumpri-la, há ainda uma última etapa na decisão a respeito de capacidade: a quantidade de assentos que estará disponível a 
cada preço. Isto ocorre porque o gerenciamento de receitas constitui-se de três pilares fundamentais: (1) diferenciação de produtos, tomando por base a segmentação de consumidores, algo que geralmente se identifica por meio de atributos observáveis escolhidos por cada passageiro para seu $v^{3}{ }^{3}$; (2) discriminação de preços, ou seja, a substituição do preço médio e único por um leque amplo de preços possíveis, com o objetivo de maximizar as receitas auferidas; (3) controle de estoque de assentos, isto é, a utilização de técnicas de alocação e controle do estoque de unidades de assentos tendo como critério as previsóes de demanda para cada voo e, assim, promovendo limites dinâmicos na quantidade de passagens disponíveis a cada segmento de mercado.

A despeito de uma empresa aérea contar com esta série de etapas de decisão quanto à capacidade a ser ofertada nos mercados em que opera, é imperioso ressaltar a existência de condições regulatórias que delimitam a liberdade das empresas aéreas.

Atendo-se aos anos mais recentes, o arcabouço regulatório que rege a atividade do transporte aéreo apresentou alterações expressivas e, dentre outros aspectos, é digno de nota que as liberdades concedidas às empresas aéreas para adicionarem destinos, frequências e tamanho médio da aeronave variaram significativamente: em 1998, encerrando a fase de Liberalização com Política de Estabilização Inativa, dois importantes instrumentos para a restrição da competição - as bandas tarifárias e a exclusividade de direitos de exploração de linhas aéreas especiais para empresas aéreas regionais - foram eliminados e houve impactos não-desprezíveis sobre a estrutura da oferta de transporte aéreo, especialmente por meio de guerras de preços. Na sequência, em 2001, segundo os termos de Oliveira (2005) atingiu-se um quadro de Quase-Desregulamentação: os preços foram totalmente liberalizados e os processos de entrada de novas empresas e de pedidos de novas linhas aéreas, frequências de voos e avióes foram flexibilizados. Novamente, sentiram-se impactos diretos sobre a oferta de transporte aéreo, uma vez que foi neste âmbito que ocorreu o surgimento de uma nova empresa aérea - a GOL Linhas Aéreas - que viria a responder por parcela significativa do mercado em poucos anos.

No entanto, anos após este movimento de Quase-Desregulamentação houve um revés à medida que políticas econômicas e setoriais formuladas pelo governo federal eram reformuladas. Neste âmbito, reativaram-se mecanismos de interferência econômica; em março e agosto de 2003, ilustrando o fenômeno da Re-regulação, o Comando da Aeronáutica, por meio do Departamento de Aviação Civil, editou

3 Dentre estes atributos, destacam-se voos com escala ou diretos, partidas em dias de semana ou em final de semana, saída de aeroportos centrais ou periféricos, opção por voar em horário de pico ou fora de horário de pico, passagens reservadas e compradas com grande ou pequena antecipação em relação ao horário do voo, previsão de longa ou curta permanência no destino etc. Todos estes atributos permitem que a empresa aérea pratique discriminação de preços de segundo grau. 
respectivamente as portarias 243/GC5 e 731/GC5: segundo os termos dos documentos, buscou-se agir de forma a adequar a oferta de transporte aéreo, feita pelas empresas aéreas, à evolução da demanda, com a finalidade de impedir uma competição danosa e irracional, com práticas predatórias de consequências indesejáveis sobre todas as empresas, tal como expresso nos documentos oficiais. Com a edição destas duas portarias, decisões empresariais centradas em questões de dimensionamento de capacidade - a importação de novas aeronaves, a implantação de novas linhas e a entrada de novas empresas aéreas no mercado - voltaram a requerer que o proponente apresentasse estudos prévios de viabilidade econômica.

Novamente, deve-se atestar que a oferta de transporte aéreo foi condicionada por possibilidades e restrições de ordem regulatória, o que evidencia o impacto que determinações desta natureza podem desempenhar sobre as condições de oferta. Como ilustração para este fato, quando a Secretaria de Acompanhamento Econômico analisou e encaminhou para julgamento uma promoção conduzida pela GOL e considerada lesiva por empresas concorrentes, dentre outros tópicos da argumentação, os órgãos apontaram fatores referentes ao período regulatório que estava em vigor para embasar a conclusão de que não haveria fundamentos para condenar a GOL de prática de preço predatório, conforme se lê a seguir:

"Verifica-se então que, se existe barreira à entrada significativa no setor aéreo (no caso a barreira regulatória), é porque o próprio órgão regulador erige tais barreiras, impedindo a expansão da oferta das empresas atuantes e de possiveis entrantes no mercado. No entanto, fazendo isso, ao mesmo tempo em que seria criado pelo regulador um ambiente que poderia ser propicio à prática de preço predatório pelo aumento das barreiras institucionais (...), a empresa supostamente predadora não teria condiçôes de expandir a sua oferta e, com isso, captar a demanda de possiveis rivais excluidas do mercado. Observe-se que a expansão da oferta seria uma condição necessária para recuperar as perdas incorridas no periodo de predação.” (SEAE/MF 2005, p. 24-25).

Enumeradas as diferentes etapas no processo de decisão quanto à capacidade produtiva da empresa aérea, e exposto como algumas destas etapas impactam as receitas e os custos de uma empresa aérea, a partir da próxima seção este artigo se aterá à identificação e à quantificação de alguns fatores econômicos que afetam a determinação do número de assentos que empresas aéreas nacionais de grande porte (majors) ${ }^{4}$, bem

4 Nesta categoria incluem-se as empresas aéreas de transporte regular de passageiros que possuem uma cobertura ampla do território nacional e operam frotas compostas por aeronaves com capacidade igual ou superior a cem assentos. As cinco empresas aéreas que pertencem a este grupo são GOL, TransBrasil $\left(^{*}\right)$, TAM, Grupo VARIG e VASP $\left({ }^{*}\right)$. $\left(^{*}\right)$ indica empresas que já encerraram suas atividades: a TransBrasil deixou de operar em dezembro de 2001 e a VASP, em janeiro de 2005. 
como em seu total, ofertam nos mercados em que operam. Propõe-se um modelo empírico contendo variáveis que buscarão identificar e explicitar a influência que alguns fatores identificados nesta seção exercem sobre o dimensionamento da oferta. As variáveis que serão incluídas no modelo, oriundas de estudos em organização industrial e também da literatura específica sobre o transporte aéreo, farão referência à estrutura de custos das empresas aéreas, à utilidade do passageiro, a aspectos macroeconômicos e regulatórios e àqueles referentes à interação existente entre as empresas que participam e competem nos mercados de transporte aéreo. No entanto, por conta da importância do tema, o foco de análise privilegiará as variáveis que se encontram sob a alçada regulatória.

\section{MODELAGEM ECONOMÉTRICA DOS DETERMINANTES DA CAPACI- DADE DAS COMPANHIAS AÉREAS}

Com o propósito de verificar a influência que aspectos econômicos e regulatórios selecionados exercem sobre a capacidade que as empresas aéreas regulares brasileiras de transporte de passageiros alocam em suas redes de ligações, este estudo proporá o seguinte modelo explicativo para a escolha da oferta de assentos de uma empresa aérea $i$, em um par de aeroportos $k$, em um tempo $t$ :

$$
\begin{aligned}
& s t_{i k t}=\beta_{0}+\beta_{1} \text { pib_real }{ }_{t}+\beta_{2} \text { cambio }_{t}+\beta_{3} d q d_{t}+\beta_{4} d q d \_g o l_{t}+\beta_{5} d q d_{-} \text {tam }_{t}+ \\
& +\beta_{6} d q d \_t b a_{t}+\beta_{7} d q d_{-} v r g_{t}+\beta_{8} d q d_{-} v s p_{t}+\beta_{9} d c s h_{t}+\beta_{10} d c s h \_g l o_{t}+\beta_{11} d c s h_{-} t a m_{t}+ \\
& +\beta_{12} d c s h \_t b a_{t}+\beta_{13} d c s h \_v r g_{t}+\beta_{14} d c s h \_v s p_{t}+\beta_{15} d c c \_m a j o r_{i k t}+\beta_{16} d c c \_r e g_{i k t}+ \\
& +\beta_{17} f t_{i k t}+\beta_{18} f t_{j k t}+\beta_{19} a d j_{f} f t_{i k t}+\beta_{20} a d j_{-} s t_{i k t}+\beta_{21} s t_{j k t}+\beta_{22} a s i z e_{i k t}+\beta_{23} a d j \_a s i z e_{i k t}+ \\
& +\beta_{24} \text { asize }_{j k t}+\beta_{25} \text { avgtscity }_{i k t}+\beta_{26} a_{\text {adj_avgtscity }}{ }_{i k t}+\beta_{27} \text { avgtscity }_{j k t}+\beta_{28} s t_{i k(t-1)}+ \\
& +\sum_{k=1}^{636} \beta_{28+k} d_{-} \text {rota }{ }_{k}+\sum_{i=1}^{19} \beta_{664+i} d_{-} e m p_{i}+\sum_{t=1}^{26} \beta_{683+t} d_{-} \text {trim }_{t}+u_{\text {likt }}
\end{aligned}
$$

O significado de cada variável encontra-se a seguir:

+ $\mathrm{st}_{\mathrm{ikt}}$ (variável dependente), $\mathrm{st}_{\mathrm{jkt}}, \mathrm{st}_{\mathrm{i}(\mathrm{t}(\mathrm{-}-\mathrm{l})}$ : número médio de assentos semanais disponibilizados pela empresa aérea $i$ na ligação $k$, na média trimestral $t . j$ representa o somatório de todos os demais competidores presentes em $k$, em $t$, excluindo a empresa $i$. (t- 1$)$ representa o período anterior a $t$. A unidade de medida de $t$ é a média semanal no trimestre.

+ avgtscity $_{\mathrm{ikt}}$, avgtscity ${ }_{\mathrm{jkt}}$ : indicador da conectividade presente nas extremidades da ligação, trata-se da média geométrica do número de assentos semanais que a 
empresa $i$ possui partindo de cada extremidade do par de aeroportos da ligação $k$, em $t . j$ representa o somatório de todos os demais competidores presentes em $k$, em $t$, excluindo a empresa $i$.

$+\mathrm{ft}_{\mathrm{ikt}}, \mathrm{ft}_{\mathrm{jkt}}$ : número médio de frequências operadas pela empresa aérea $i$ na ligação $k$ em $t$. Novamente, $j$ representa o somatório de todos os demais competidores presentes em $k$, em $t$, excluindo a empresa $i$.

† asize $_{\mathrm{ikt}}$, asize $_{\mathrm{jkt}}$ : tamanho médio da aeronave utilizada pela empresa aérea $i$ na ligação $k$, em $t . j$ possui o significado usual.

+ pib_real : valor do PIB nacional real em $t$;

+ cambio : câmbio efetivo em $t$;

$+\mathrm{dqd}_{\mathrm{t}}$ : variável binária indicando o segundo período regulatório de interesse, a fase chamada de "Quase-Desregulamentação" por Oliveira (2005) e que esteve em prática entre o terceiro trimestre de 2001 e o primeiro trimestre de 2003;

$+\mathrm{dcsh}_{\mathrm{t}}$ : variável binária indicando o período durante o qual vigorou o acordo de code-share entre a TAM e a VARIG (primeiro trimestre de 2003 ao final da amostra, no quarto trimestre de 2004);

† dcc $_{\mathrm{ikt}}$ : variável binária indicando se o voo é operado utilizando um aeroporto central em pelo menos uma das extremidades do par de aeroportos. Os sufixos "major" e "reg" isolam o efeito deste atributo para cada parcela relevante da amostra: empresas de grande porte e empresas aéreas de pequeno porte/regionais. São considerados aeroportos centrais os seguintes: Congonhas (São Paulo), Pampulha (Belo Horizonte) e Santos Dumont (Rio de Janeiro);

Finalmente, incluíram-se também no modelo variáveis binárias destinadas a capturar e controlar os efeitos específicos que a empresa aérea $\left(\mathrm{d}_{-} \mathrm{emp}_{\mathrm{i}}\right)$, a ligação $\left(\mathrm{d}_{-}\right.$rota $\left.\mathrm{k}\right)$ e o trimestre $\left(d_{-}\right.$trim ${ }_{t}$ ) geram sobre a decisão de alocação de capacidade da empresa aérea na rota.

Os índices $i, k$ e $t$ referem-se, respectivamente, a empresa aérea, ligação e tempo. O prefixo "adj_" indica a variável que a segue referente ao aeroporto adjacente, nos casos das cidades de Belo Horizonte, Rio de Janeiro e São Paulo, onde existem dois aeroportos a partir dos quais empresas aéreas comerciais operam voos regulares. Sua formulação foi inspirada pelo tratamento que trabalhos como Morrison (2001) deram à concorrência intrarrotas e, no âmbito do modelo proposto, é coerente com a inclusão da variável dcc ikt. Os sufixos "glo", "tba”, "tam”, "vrg” e "vsp" referem-se 
às empresas aéreas GOL, TransBrasil, TAM, Grupo VARIG e VASP. Desta forma, as variáveis "dcsh_(empresa aérea)" e "dqd_(empresa aérea)" são termos de interação que identificam os efeitos que o code-share entre a TAM e a VARIG e o período de Quase-Desregulamentação, respectivamente, exerceram sobre cada empresa aérea nacional de grande porte.

A variável PIB real foi construída a partir de dados nominais provenientes do Instituto Brasileiro de Geografia e Estatística (IBGE), trazidos a valor presente pela aplicação do Índice Nacional de Preços ao Consumidor Amplo (IPCA). A taxa de câmbio efetiva provém de informações fornecidas pelo Banco Central do Brasil. Quanto aos dados referentes ao volume e à morfologia da oferta, estes provêm dos Relatórios Hotran divulgados periodicamente pelo Departamento de Aviação Civil e foram obtidos mediante a manipulação desta base de dados, acumulados de forma trimestral ao longo do período contemplado na amostra: terceiro trimestre de 1998 ao quarto trimestre de 2004, o que perfaz 26 trimestres. Trata-se de um banco de dados inédito, cujas extensão e diversidade permitem diversos experimentos em organização industrial empírica.

Para este estudo, foram consideradas somente as ligações existentes entre os 30 maiores aeroportos nacionais em termos de oferta. Estes aeroportos - cuja enumeração encontra-se no Anexo 1 - foram obtidos somando-se os assentos domésticos semanais que passam por cada terminal, seja em movimento de partida, seja de chegada. Este conjunto de 30 aeroportos responde por cerca de $90 \%$ dos assentos domésticos semanais. No período amostrado, houve 19 empresas aéreas regulares prestando serviço de transporte de passageiros entre estes aeroportos, em um total de 636 ligações existentes. ${ }^{5}$ No total, trabalhou-se com 25.079 observações, sendo 2.521 referentes à empresa GOL, 6.071 referentes à TAM, 2.198 referentes ao Grupo TransBrasil, 6.427 referentes à VASP e 6.662 referentes às empresas que compóem o Grupo VARIG. As demais 14 empresas aéreas contidas na amostra responderam por somente $5 \%$ das observações. Deve-se ressaltar que o termo "observação" refere-se a haver operação regular da empresa aérea $i$ na ligação $k$ em algum momento do trimestre, o que não guarda relação direta com aspectos como o número de frequências operadas, o tamanho das aeronaves utilizadas ou a presença de escalas na ligação. Não foram geradas ligações possíveis mediante conexão, ou seja, que envolvessem a troca de aeronaves e a mudança do número do voo.

Estatísticas descritivas para as variáveis contínuas estão apresentadas na Tabela 1. Sendo variáveis em nível referentes a grandezas econômicas e naturais, nenhuma

5 Ligaçóes unidirecionais entre aeroportos. Sob este critério, a ligação (em termo equivalente, o mercado) entre Congonhas e Santos Dumont é tratada separadamente da ligação entre Santos Dumont e Congonhas. 
dessas variáveis apresenta média negativa. No entanto, a modelagem econométrica permitirá evidenciar que algumas destas variáveis apresentam impacto negativo sobre a determinação do valor da variável dependente, notadamente a variável cambial e algumas das variáveis referentes ao somatório dos demais competidores e às alternativas substitutas.

TABELA 1 - ESTATÍSTICAS DESCRITIVAS

\begin{tabular}{lccrr}
\hline Variável & Média & Desvio Padrão & Mínimo & Máximo \\
\hline st & 1670.361 & 2087.389 & 10 & 29883 \\
pib_real & 412552.6 & 28371.55 & 355256.2 & 478341 \\
cambio & 106.7558 & 10.06835 & 90.00387 & 124.1592 \\
$\mathrm{ft}$ & 14.08461 & 17.69054 & .3333333 & 561 \\
$\mathrm{ftj}$ & 32.26044 & 48.97289 & 0 & 765 \\
adj_ft & 25.8393 & 75.24582 & 0 & 960.5 \\
stj & 3875.354 & 5954.169 & 0 & 71441.34 \\
adj_st & 3089.364 & 9262.962 & 0 & 103727.7 \\
asize & 117.2253 & 33.98453 & 4 & 325 \\
asizej & 98.37333 & 50.78758 & 0 & 285 \\
adj_asize & 41.51078 & 57.62378 & 0 & 285 \\
avgtscity & 22223.65 & 22373.64 & 60 & 157463 \\
avgtscityj & 45842.1 & 50132.03 & 0 & 327219.7 \\
adj_avgtscit & 39762.12 & 76522.77 & 0 & 633434 \\
\hline
\end{tabular}

Diferentemente de outras abordagens usualmente encontradas para a resolução do problema de alocação de aviões e frequências (como HSU; WEN, 2003 e SHERALI, BISH; ZHU, 2006), esta pesquisa não utilizou programação linear como método de resolução, mas sim técnicas econométricas para realizar a estimação dos coeficientes da equação (1). A razão desta opção metodológica por análise de regressão múltipla com dados em painel deve-se ao fato de esta ser a abordagem habitualmente empregada em estudos sobre organização industrial empírica e, ademais, por possibilitar a inclusão de considerações sobre aspectos regulatórios e concorrenciais de forma simples e de interpretação objetiva.

As variáveis contidas no modelo exercem efeito potencial sobre o total de assentos colocados por uma empresa aérea em uma rota, por meio de deslocamentos de receitas ou de custos da empresa aérea, o que altera a lucratividade esperada com a decisão da oferta. Atendo-se primeiramente às variáveis operacionais, espera-se que a concentração de assentos ofertados pelas empresas nas extremidades da ligação possua impacto positivo sobre o dimensionamento da oferta na ligação. Esta é uma hipótese condizente com o efeito que a conectividade da rede de uma empresa aérea 
exerce sobre a elevação no nível de serviço destinado aos passageiros locais e à atração de tráfego não-local para a ligação. Esta hipótese corresponde aos efeitos que hubs apresentam no estímulo da demanda (por meio da redução do schedule delay) e no adensamento das ligações: multiplicando destinos e frequências de voos, uma parcela de mercado maior pode ser alcançada. Grande número de estudos em economia dos transportes já encontrou evidências deste efeito, a exemplo de Brueckner e Zhang (2001).

Ainda no que se refere às variáveis operacionais e concorrenciais, espera-se que o tamanho médio da aeronave e o número de frequências operadas pela própria empresa aérea apresentem contribuições positivas para a oferta de assentos nos mercados, mas que a magnitude do efeito advindo da variável referente a frequências supere a magnitude do efeito advindo da variável referente ao tamanho da aeronave. Este é um resultado condizente com o efeito multiplicador que a rede provê à empresa aérea justamente pela contribuição ao adensamento das ligações, algo em compasso com a importância estratégica que o número de frequências operadas possui; diferentes estudos já encontraram evidências de que o número de frequências pode ser uma variável de jogo na competição entre empresas aéreas. ${ }^{6}$ Por esta mesma razão, espera-se que estas variáveis, quando avaliadas para as empresas aéreas concorrentes $(j)$, forneçam uma indicação geral quanto ao padrão de concorrência entre as empresas aéreas nacionais, muito embora se reconheça que avaliações mais precisas requereriam uma modelagem formalmente derivada de equações de demanda e de oferta, posteriormente desenvolvida sobre uma base de dados com informações de oferta e de demanda (preços e quantidades). Pela limitação da base de dados, esta pesquisa não enveredou por esta trilha, o que exige que a leitura dos resultados acerca da interação estratégica possua um caráter sugestivo, ao invés de conclusivo. Finalmente, as variáveis que fazem referência às observações em aeroportos adjacentes permitirão obter evidências quanto ao efeito que a substitutibilidade relativa de aeroportos (sob a perspectiva do passageiro) exerce sobre o planejamento da oferta das empresas aéreas.

Quanto às variáveis econômicas e sobre as quais a empresa aérea não possui domínio, espera-se obter sinal positivo para o coeficiente do Produto Interno Bruto, algo que se deve à hipótese de o transporte aéreo apresentar uma correlação positiva com o nível de atividade econômica, acompanhando o estímulo que esta grandeza eco-

6 Estudos em economia do transporte aéreo fornecem evidências variadas acerca da interação estratégica entre as empresas aéreas e as variáveis de jogo que estas utilizam, notadamente preços (competição de Bertrand), quantidades (competição de Cournot) e capacidade (competição de Edgeworth e modelos em dois estágios). Especificamente no que se refere à competição em quantidades e em capacidade, os trabalhos de Brander e Zhang (1990), Salvanes, Steen e Sorgard (2003) e Goolsbee e Syverson (2005) obtiveram evidências de que empresas aéreas competem em frequências, distinguindo-se, inclusive, a entrada em cada extremo da ligação e a entrada na própria ligação, bem como a investigação quanto ao timing das reações sob cada forma de ameaça de uma empresa entrante. 
nômica apresenta sobre a demanda por transporte aéreo. No que se refere à variável cambial, deve-se separar dois efeitos: atendo-se à ótica do produtor, espera-se que a valorização da moeda nacional seja um fator de estímulo para a oferta de voos, pois custos de arrendamento de aeronaves, de importação de peças de manutenção e de insumos diversos cotados em moeda estrangeira podem ser mais bem suportados pelas empresas aéreas nacionais; atendo-se à ótica do consumidor, uma vez que os preços relativos de passagens sofrem impactos de variações cambiais, espera-se observar inversões nos fluxos de passageiros nacionais e internacionais na presença de diferentes níveis de taxa de câmbio. No entanto, pelo fato de a amostra conter somente voos domésticos, assume-se que os efeitos da variação cambial sobre a oferta de assentos por meio da variação da demanda por transporte aéreo sejam diminutos. Desta forma, espera-se que o efeito preponderante ocorra diretamente sobre as condiçốes de oferta (preço de insumos), sem a existência significativa de impactos intermediados pela variação da demanda, o que conduz a um sinal negativo esperado, sem ambiguidades.

Quanto às variáveis binárias referentes ao período regulatório - apresentadas como termos de interação com as principais empresas aéreas nacionais - não se espera um sinal em particular, mas sim que apresentem significância, uma vez que o período ao qual fazem referência foi marcado pelo acréscimo de liberdade às empresas aéreas e de estímulo à concorrência. Quanto às variáveis indicativas do período durante o qual vigorou o acordo de compartilhamento de assentos entre a TAM e a VARIG, esperam-se sinais negativos, condizentes com o resultado que modelos teóricos sobre competição em oligopólios predizem quando existe um aumento na concentração dos produtores. Quanto à última das variáveis binárias incluídas no modelo - a que indica se a ligação possui um aeroporto central em pelo menos uma das extremidades -, espera-se que isto se traduza em estímulo ao número de voos, devido à natureza de passageiros time-sensitive que caracterizam ligações a partir de aeroportos localizados próximo ao centro destas cidades. No entanto, nestes aeroportos podem eventualmente ocorrer efeitos restritivos sobre o tamanho da operação da empresa aérea: dada a mesma localização central, estes três aeroportos impóem limites à operação de aeronaves de grande porte, especialmente devido ao comprimento de suas pistas e a normas que impedem a utilização do aeroporto em horários noturnos pela proximidade de áreas residenciais.

A estimação da equação (1), a qual expressa a quantidade semanal de assentos na média do trimestre que uma empresa aérea disponibiliza nas ligações em que está presente $\left(s t_{i k t}\right)$, foi realizada utilizando-se o software Stata 9.2, com o estimador de mínimos quadrados ordinários com desvio padrão robusto à heteroscedasticidade (Newey-West). Os resultados obtidos encontram-se na Tabela 2. 
TABELA 2 - MODELO DE FORMAÇÃO DE CAPACIDADE (OFERTA DE ASSENTOS - ST)

\begin{tabular}{|c|c|c|c|}
\hline Variável & $\begin{array}{l}\text { Parâmetro Estimado - Nível de Significância } \\
\text { (Desvio padrão Estimado) }\end{array}$ & Variável & $\begin{array}{l}\text { Parâmetro Estimado - Nível de Significância } \\
\text { (Desvio padrão Estimado) }\end{array}$ \\
\hline st (t-1) & $\begin{array}{l}0.543 \ddagger \\
(0.065)\end{array}$ & dcc_reg & $\begin{array}{c}-140.519 \dagger \\
(69.645)\end{array}$ \\
\hline pib_real & $\begin{array}{l}0.001 \ddagger \\
(0.000)\end{array}$ & $f t$ & $\begin{array}{l}42.867 \ddagger \\
(10.444)\end{array}$ \\
\hline cambio & $\begin{array}{l}-5.538 \ddagger \\
(1.096)\end{array}$ & $\mathrm{ftj}$ & $\begin{array}{l}1.912 \dagger \\
(0.971)\end{array}$ \\
\hline$d q d$ & $\begin{array}{l}-31.614 \\
(44.156)\end{array}$ & adj_ft & $\begin{array}{l}0.953^{*} \\
(0.971)\end{array}$ \\
\hline$d q d \_g l o$ & $\begin{array}{l}-54.671 \\
(95.272)\end{array}$ & stj & $\begin{array}{l}-0.040 \ddagger \\
(0.010)\end{array}$ \\
\hline dqd_tam & $\begin{array}{l}-49.346 \text { * } \\
(26.014)\end{array}$ & adj_st & $\begin{array}{l}-0.038 \ddagger \\
(0.005)\end{array}$ \\
\hline$d q d$ tba & $\begin{array}{c}-164.798 \ddagger \\
(55.559)\end{array}$ & asize & $\begin{array}{l}6.631 \ddagger \\
(0.913)\end{array}$ \\
\hline$d q d \_v r g$ & $\begin{array}{c}32.725 \\
(24.818)\end{array}$ & asizej & $\begin{array}{c}0.149 \text { * } \\
(0.085)\end{array}$ \\
\hline$d q d \_v s p$ & $\begin{array}{l}23.982 \\
(24.339)\end{array}$ & adj_asize & $\begin{array}{l}-0.787 \\
(0.159)\end{array}$ \\
\hline$d c s h$ & $\begin{array}{c}-331.004 \ddagger \\
(56.455)\end{array}$ & avgtscity & $\begin{array}{c}0.011 \\
(0.002)\end{array}$ \\
\hline dcsh_glo & $\begin{array}{r}-114.500 \\
(96.104)\end{array}$ & avgtscityj & $\begin{array}{c}0.003 \\
(0.000)\end{array}$ \\
\hline dcsh_tam & $\begin{array}{l}-74.886 \dagger \\
(33.240)\end{array}$ & adj_avgtscit & $\begin{array}{c}0.001 \\
(0.000)\end{array}$ \\
\hline dcsh_vrg & $\begin{array}{c}116.474 \ddagger \\
(28.041)\end{array}$ & cons & $\begin{array}{r}14.508 \\
(205.787)\end{array}$ \\
\hline$d c s h \_v s p$ & $\begin{array}{l}104.552 \ddagger \\
(24.027)\end{array}$ & & \\
\hline dcc_major & $\begin{array}{l}-73.176 \ddagger \\
(28.038)\end{array}$ & & \\
\hline
\end{tabular}

R2 Ajustado: 0.971.

Notas: Efeitos fixos omitidos; desvio padrão em parênteses;

* significante ao nível de $10 \%$; † significante ao nível de 5 \%; † significante ao nível de 1 \%.

Os resultados obtidos, apresentados na Tabela 2, evidenciam que a conectividade da ligação (representada pelas variáveis avgtscity ${ }_{i k t}$ ) não parece ser um atributo intrínseco de estímulo na quantidade de assentos colocados à disposição do mercado, uma vez que não apresentou significância estatística. Possivelmente, sua significância é capturada por meio das variáveis binárias de ligação para os casos em que este 
aspecto é determinante. $\mathrm{O}$ mesmo raciocínio se aplica à conectividade da ligação das empresas rivais e da ligação partindo de algum aeroporto adjacente (variáveis avgtscity $_{\text {jkt }}$ e adj_avgtscit ${ }_{\text {ikt }}$ ).

$\mathrm{O}$ número de frequências próprias $\left(\mathrm{ft}_{\mathrm{ikt}}\right)$ e o tamanho médio da aeronave (asize $\mathrm{i}_{\mathrm{ikt}}$ ) utilizada contribuem conjuntamente para o aumento no número de assentos oferecidos em uma ligação, conforme indicam a significância estatística e o sinal esperado (positivo): 42,8 e 6,6, respectivamente. No entanto, conforme esperado, o efeito do número de frequências supera o efeito do tamanho da aeronave $(42,8>6,6)$, algo que parece corroborar a interpretação segundo a qual o número de frequências é uma variável estratégica para as empresas aéreas. $\mathrm{O}$ tamanho da operação própria em aeroportos adjacentes, medida sob a forma de número total de assentos ofertados (adj_st $t_{\text {ikt }}$ ), com coeficiente estimado de $-0,038$, é um fator de desestímulo da oferta da empresa aérea, algo coerente com a interpretação de que, para os passageiros que os utilizam, aeroportos adjacentes são substitutos em algum grau. No entanto, o tamanho da aeronave utilizada na ligação a partir do aeroporto adjacente (adj_asi$\mathrm{ze}_{\mathrm{ikt}}$ ) não impacta a oferta de assentos e, quanto ao número de frequências operadas $\left(\operatorname{adj}_{-} \mathrm{ft}_{\mathrm{ikt}}\right)$, o impacto desta variável é apenas marginal, com coeficiente estimado de 0,95 . Este resultado, paradoxal perante o coeficiente estimado para adj_st ${ }_{i k t}$, deve-se possivelmente a alguma correlação espúria existente nas cidades em que esta variável existe (cidades com alta densidade de tráfego e número elevado de operações), embora a baixa significância estatística minimize sua importância.

No que concerne à presença de empresas aéreas rivais na ligação, verifica-se um resultado curioso: a quantidade de assentos de uma empresa aérea aumenta conforme as rivais aumentam o tamanho médio da aeronave dedicada à realização da ligação em questão (asize $\mathrm{jkt}_{\mathrm{k}}$ ) e também à medida que o número de frequências operadas pelas concorrentes aumenta $\left(\mathrm{ft}_{\mathrm{ikt}}\right)$. Possivelmente, este comportamento se deva a um efeito de sinalização que as rivais exercem. Estes seriam indicativos de que a demanda existente na ligação possui vitalidade e, sobretudo, rentabilidade. No entanto, a quantidade total de assentos oferecidos na ligação por empresas rivais $\left(s_{\mathrm{jkt}}\right.$ ), cujo coeficiente estimado é de -0,04, é um fator de decréscimo para a capacidade que uma empresa aérea aloca na ligação. Este fato pode eventualmente evidenciar que a empresa aérea distingue trade-offs (acréscimo de frequências em detrimento do tamanho médio da aeronave, ou vice-versa) na forma de operação das empresas rivais, de forma a diferenciar este tipo de ação de ações que signifiquem a expansão bruta de assentos rivais na rota.

Voltando a atenção para variáveis fora do alcance da empresa aérea, um primeiro aspecto a se notar é a restrição que os aeroportos centrais impõem à oferta de assentos em voos que o utilizam como pelo menos uma das extremidades. Este 
resultado afeta todas as empresas aéreas, mas particularmente as empresas aéreas regionais (dcc_reg), cujo coeficiente estimado é quase duas vezes maior que o coeficiente estimado para empresas aéreas de grande porte ${ }^{7}$ (dcc_major). Esperava-se que estes aeroportos, por sua localização próxima a centros geradores de demanda com menor sensibilidade ao preço e maior sensibilidade à conveniência de horários, estimulassem o número de assentos oferecidos pelas empresas aéreas. No entanto, estes aeroportos impõem restriçóes operacionais às empresas aéreas e, por esta razão, pode haver um descompasso entre a oferta realizada e a demanda potencial. Deve-se notar, no entanto, que a restrição que estes terminais impõem às pequenas empresas supera significativamente a restrição com que se defrontam as grandes empresas. Esta constatação faz levantar a hipótese de que haja restrições ao acesso das pequenas empresas a estes aeroportos, fenômeno que, caso corresponda à realidade, já teria sido revertido em Belo Horizonte (Pampulha) e Rio de Janeiro (Santos Dumont), cidades onde ocorreu um redirecionamento destes aeroportos centrais para o uso em ligações regionais, menos densas.

Outro aspecto que os dados revelam é que o período da Quase-Desregulamentação (variáveis com prefixo "dqd_") pouco impactou a oferta de assentos realizada pelas empresas aéreas regulares, exceto para o caso da TAM (marginalmente) e da TransBrasil (significativamente). No caso da empresa TAM, este fato possivelmente coincide com alguns problemas de imagem pública que a empresa enfrentou durante o período, notadamente uma série de incidentes envolvendo suas aeronaves. Já no que se refere à TransBrasil, deve-se destacar que a empresa estava em processo de encerramento de suas atividades, o que possivelmente altera o efeito do marco regulatório. Desta forma, os impactos desta mudança regulatória parecem ter sido tênues.

Um resultado muito significativo - tanto em termos estatísticos quanto econômicos - foram as estimativas para os parâmetros referentes ao code-share entre as empresas TAM e VARIG. Este acordo significou uma redução global na quantidade de assentos oferecidos, muito embora algumas empresas tenham acentuado esta tendência (casos da GOL e da TAM) enquanto outras tenham amenizado este movimento (casos da VARIG e VASP). Procede, portanto, que órgãos brasileiros de defesa da concorrência tenham demonstrado sua preocupação com as consequências deste acordo.

7 A definição de empresa aérea de grande porte originalmente designa as empresas aéreas que, durante o período de regulação com política industrial (1973-1986), foram incumbidas de voar linhas aéreas nacionais-tronco e voos internacionais: Cruzeiro do Sul, TransBrasil, VARIG e VASP integravam esta lista. Embora a nomenclatura tenha perdido parcela de seu poder classificatório, inclusive por conta de alterações regulatórias relevantes ao longo das últimas décadas, o termo "empresas aéreas de grande porte" geralmente contrapõe-se às empresas aéreas de pequeno porte, comumente chamadas de "empresas aéreas regionais". 
Nesta altura, surge uma aparente contradição: por um lado, a quase-desregulamentação pouco impactou a oferta de assentos. Porém, por outro, o code-share entre VARIG e TAM impactou-a fortemente. Neste contexto, o efeito da competição sobre a determinação da capacidade parece dúbio. Novamente, deve-se ressaltar que, na falta de uma abordagem estrutural para o problema modelado, não é possível afirmar categoricamente qual seria o efeito da competição sobre a determinação da capacidade; só é possível obter resultados sugestivos. Adicionalmente, convém recordar que a quase-desregulamentação flexibilizou outras variáveis de jogo além da capacidade, incluindo preços, e que, em sua vigência, houve a entrada da GOL nos mercados aéreos domésticos, cuja variável estratégica (ao menos no estágio reputacional) era preço, por excelência. Desta forma, uma possibilidade de explicação recorre ao fato de, durante o período da quase-desregulamentação, as empresas aéreas estarem mais voltadas para alterações na variável preço, ao invés da capacidade.

Finalmente, as duas variáveis macroeconômicas - PIB e câmbio - apresentaram resultados bastante satisfatórios, tanto no que se refere à significância das estimativas quanto ao sinal dos parâmetros: o crescimento econômico relaciona-se com a expansão na oferta de assentos das empresas regulares em uma magnitude que, em termos de elasticidade (obtida no ponto médio da amostra), corresponde a um incremento de 0,29\% no número de assentos ofertados (desvio padrão de 0,09) para cada aumento de $1 \%$ do PIB. Justapondo este resultado a estimativas existentes quanto à elasticidade-renda do transporte aéreo nacional (usualmente considerada entre 1,5 e 2,0), obtém-se um indicativo de que, em épocas de crescimento econômico, haveria uma tendência a um aumento no fator de aproveitamento das aeronaves, fruto de uma oferta de assentos que cresce menos que proporcionalmente perante o incremento da demanda por transporte aéreo. As razões para este fenômeno são possivelmente a natureza concessionária do transporte aéreo e a especificidade dos fatores de produção envolvidos na oferta de assentos - aeronaves e tripulações - que inibem expansões automáticas na capacidade instalada nos mercados em que a empresa aérea está presente.

No que concerne à relação entre a oferta de assentos e o valor da moeda nacional, obtiveram-se o sinal negativo e a significância que se esperava, algo coerente com a importância que as alíneas de custos cambiais (referentes sobretudo a despesas com leasing de aeronaves e compra de material de manutenção) e com combustível (insumo cotado em moeda internacional) representam para as empresas aéreas nacionais. Segundo dados do Anuário do Transporte Aéreo do Departamento de Aviação Civil (2004), 50\% dos custos operacionais das empresas aéreas nacionais concentram-se nas duas alíneas referidas. Em termos de elasticidade (novamente obtida no ponto médio da amostra), obteve-se que uma valorização de $1 \%$ no câmbio relaciona-se com uma redução da oferta de assentos em $0,35 \%$ (desvio padrão de 0,07 ), um resul- 
tado que demanda atenção, especialmente no cenário de grande volatilidade cambial a que a economia brasileira está sujeita desde a liberalização cambial ocorrida no início de 1998. Assim, a capacidade produtiva deste setor é encolhida (expandida) por episódios de desvalorização (valorização) cambial, mas em uma variação que é menos do que proporcional. Tanto a inelasticidade da oferta com relação ao câmbio quanto ao PIB eram esperadas a priori, sendo consistentes com o fato de se tratar de aviação regular, ou seja, aquela na qual as companhias se comprometem a manter uma programação horária de voo relativamente fixa, independentemente de choques exógenos.

\section{CONCLUSÕES}

A pesquisa buscou identificar e quantificar fatores que influenciam a decisão de empresas aéreas nacionais na oferta de assentos nas ligações em que estão presentes com voos regulares.

Controlando-se por fatores que representam condicionantes concorrenciais e operacionais do dimensionamento da capacidade que empresas aéreas alocam nos mercados em que operam, pôde-se verificar que a alteração regulatória introduzida em 2001, com o movimento de Quase-Desregulamentação, não surtiu resultados significativos no que concerne à oferta das empresas aéreas nacionais. Em sentido contrário, ficou evidente que o período durante o qual vigorou o acordo de codeshare entre as duas maiores empresas aéreas regulares do País - a TAM e a VARIG - houve expressiva redução na oferta de assentos de praticamente todas as empresas aéreas nacionais, resultado condizente com o efeito previsto em modelos estilizados que expressam a concentração da oferta. Outro fator igualmente importante e significativo diz respeito ao acesso a aeroportos centrais. Encontraram-se evidências de que há restrições ao acesso de empresas aéreas regionais, o que sugere haver baixa contestabilidade destes terminais, que concentram fundamentalmente a operação de empresas aéreas de grande porte.

No entanto, deve-se registrar cautela na interpretação da variável referente ao acordo de compartilhamento de assentos entre a VARIG e a TAM: o período durante o qual este acordo vigorou coincidiu com a fase da Re-regulação. Desta forma, o efeito capturado por esta variável binária no modelo capta também as particularidades que o momento regulatório impunha. Desta maneira, deve-se observar que, ao efeito do code-share (restrição voluntária da capacidade), somou-se uma restrição involuntária sobre a expansão da capacidade das empresas aéreas, vinda por decreto. Todavia, uma vez que o efeito estimado obtido foi negativo, pode-se assumir que a variável 
identifica de forma representativa uma redução na capacidade ofertada, e não uma interrupção em planos de expansão. Desta forma, a variável mantém sua robustez na captura do efeito do code-share sobre a oferta de assentos.

\section{REFERENCIAS}

BOGUSLASKI, C.; ITO, H.; LEE, D. Entry patterns in the Southwest Airlines route system. Review of Industrial Economics, Issue 25, p. 317-350, 2004.

BORENSTEIN, S. Hubs and high fares: dominance and market power in the U.S. airline industry. The RAND Journal of Economics, v. 20, issue 3, p.344-365, 1989.

BRANDER, J.; ZHANG, A. Market conduct in the airline industry: an empirical investigation. The RAND Journal of Economics, v. 21, issue 4, p.567-583, 1990.

BRUECKNER J. K.; ZHANG Y. A model of scheduling in airline networks: how a hub-and-spoke system affects flight frequency, fares and welfare. Journal of Transport Economics and Policy, v. 35, n. 2, p. 195-222, 2001.

DEPARTAMENTO DE AVIAÇÃO CIVIL. Portaria 243/GC5, 2003. . Portaria 731/GC5, 2003. . Anuário do Transporte Aéreo - Dados Econômicos, 2004

EVANS, W.; KESSIDES, I. Localized market power in the U.S. airline industry. The Review of Economics and Statistics, v.75, issue 1, p. 66-75, 1993.

GOOLSBEE, A.; SYVERSON, C. How do incumbents respond to the threat of entry? Evidence from major airlines. Cambridge, MA: National Bureau of Economic Analysis, 2005. (Working Paper 11072).

HSU, C-I.; WEN, Y-H. Determining flight frequencies on an airline network with demand-supply interactions. Transportation Research Part E, issue 39, p. 417441, 2003.

LOVADINE, D.; OLIVEIRA, A. V. M. A desregulamentação da aviação civil no Brasil. In: SALGADO, L. H.; DA MOTTA, R. S. (Eds.) Marcos regulatórios no Brasil: o que foi feito e o que falta fazer. Rio de Janeiro: IPEA, 2005, p. 245283.

MORRISON, S. Actual, adjacent, and potential competition: estimating the full effect of Southwest Airlines. Journal of Transport Economics and Policy, issue 35, p. 239-256, 2001.

OLIVEIRA, A. V. M. Performance dos regulados e eficácia do regulador: uma avaliação das politicas regulatórias do transporte aéreo e dos desafios para o futuro. Documento de Trabalho n. 007 - Acervo Científico do Núcleo de Estudos em Competição e Regulação do Transporte Aéreo (NECTAR). São José dos Campos, SP, 2005. Disponível em: http://www.nectar.ita.br/. 
OUM, T. H; ZHANG, A.; ZHANG, Y. Airline network rivalry. The Canadian Journal of Economics, v. 28, issue 4a, p. 836-857, 1995.

RÖLLER, L-H.; SICKLES, R. Capacity and product market competition: measuring market power in a "puppy-dog" industry. Wissenschaftszentrum Berlin Für Sozialforschung, Discussion Paper FS IV 97-31, 1997.

SALVANES, K.; STEEN, F; SORGARD, L. Collude, compete or both? Deregulation in the Norwegian airline industry. Journal of Transport Economics and Policy, v. 37, n. 3, p. 383-416, 2003.

SEAE/MF - Secretaria de Acompanhamento Econômico/Ministério da Fazenda. Nota técnica n 29/2004/COGDC-DF/SEAE/MF, 2004.

. Nota informativa $n^{\circ}$ 55/2005 COGDC-DF/SEAE/MF, 2005.

SHERALI, H.; BISH, E.; ZHU, X. Airline fleet assignment concepts, models and algorithms. European Journal of Operational Research, issue 172, p.1-30, 2006.

WEI, W.; HANSEN, M. Cost economics of aircraft size. Journal of Transport Economics and Policy, 37 (part 2), p. 279-296, 2003.

. Impact of aircraft size and seat availability on airlines' demand and market share in duopoly markets. Transportation Research Part E, issue 41, p. 315-327, 2005. 
ANEXO 1 - 30 AEROPORTOS COM MAIOR OFERTA DE ASSENTOS NACIONAIS (1998-2004)

SBAR - Aracaju (SE);

SBBE - Belém (PA);

SBBH - Belo Horizonte / Pampulha (MG);

SBBR - Brasília (DF);

SBCF - Belo Horizonte / Confins (MG);

SBCG - Campo Grande (MS);

SBCT - Curitiba (PR);

SBCY - Cuiabá (MT);

SBEG - Manaus (AM);

SBFI - Foz do Iguaçu (PR);

SBFL - Florianópolis (SC);

SBFZ - Fortaleza (CE);

SBGL - Rio de Janeiro / Galeão (RJ);

SBGO - Goiânia (GO);

SBGR - São Paulo / Guarulhos (SP);

SBJP - João Pessoa (PB);

SBKP - Campinas (SP);

SBLO - Londrina (PR);

SBMO - Maceió (AL);

SBMQ - Macapá (AP);

SBNF - Navegantes (SC);

SBNT - Natal (RN);

SBPA - Porto Alegre (RS);

SBRF - Recife (PE);

SBRJ - Rio de Janeiro / Santos Dumont (RJ);

SBSL - São Luís (MA);

SBSP - São Paulo / Congonhas (SP);

SBSV - Salvador (BA);

SBTE - Teresina (PI);

SBVT - Vitória (ES). 